\title{
A rare case of chronic ectopic pregnancy: a diagnostic enigma
}

\author{
Prativa Sadangi, Kumari Ranjeeta*, Manasi Jena
}

Department of Obstetrics and Gynecology, Ispat General Hospital, Rourkela, Odisha, India

Received: 09 August 2020

Accepted: 05 November 2020

\section{*Correspondence:}

Dr. Kumari Ranjeeta,

E-mail: ranjita78700@gmail.com

Copyright: () the author(s), publisher and licensee Medip Academy. This is an open-access article distributed under the terms of the Creative Commons Attribution Non-Commercial License, which permits unrestricted non-commercial use, distribution, and reproduction in any medium, provided the original work is properly cited.

\section{ABSTRACT}

Clinical presentation of chronic ectopic pregnancy is often vague and confusing. Because of this diagnosis becomes delayed and difficult. Here we present one such case, reporting to our hospital. The low resource set up led to limitations in our approach and here we point out the factors which led to the diagnostic dilemma. We are reporting this case because similar challenges can be faced by other clinician in our field.

Keywords: Chronic ectopic pregnancy, Teratoma, Dilatation, Evacuation

\section{INTRODUCTION}

An ectopic pregnancy is one in which the fertilized ovum get implanted in a site other than the normal uterine cavity. Ectopic pregnancy is the consequence of an abnormal implantation of the blastocyst which, in over $95 \%$ of cases, implants in the fallopian tube, most commonly the ampullary region. ${ }^{1,2}$

A chronic ectopic pregnancy (CEP) occurs when trophoblastic tissue invades the implanted structure, causing a protracted destruction at the site of attachment, resulting in repeated rupture and minor bleeding. Over time, a haematocele is formed, leading to an inflammatory reaction and the generation of chronic pelvic adhesions which resemble a complex pelvic mass. ${ }^{3}$ Due to advances in ultrasonic imaging have significantly improved the detection rate of ectopic pregnancy, offering patients the option of non-surgical treatment. Here we present a rare case of a young woman who came to our department for the treatment of tumor suspicious of teratoma but was diagnosed histologically with CEP following laparotomy.

\section{CASE REPORT}

A patient of age 27 years, gravida 2, para 1, came to gynaecology outpatient department (OPD) with complaint of pain lower abdomen especially more on right side, associated with bleeding per vaginum for last 12 days. She had history of intake of medical termination of pregnancy (MTP) kit, 17 days back, followed by dilatation and evacuation in private nursing home 15 days back. She came with USG scan report suggestive of mixed ovarian mass of size $8.7 \times 8.0 \mathrm{~cm}$ in left ovarian fossa, suspicious of teratoma of left ovary. She admitted in our institute for further evaluation and management. Her urine pregnancy test (UPT) was faintly positive on admission. She was married since last 4 years and had one male child of 3 years born by emergency lower segment caesarean section (LSCS) for cephalopelvic disproportion (CPD) in labour in our institute. Her past menstrual cycles were regular. There was no history suggestive of prior pelvic infection or endometriosis. She was a non-smoker and was practicing barrier method of contraception by husband. She had no significant past medical history.

On clinical examination, pulse rate was 100 beats per minute, blood pressure $90 / 70 \mathrm{mmHg}$ in supine position, and severely pale. On per abdominal examination uterine size could not be elicited a mass of size $6 \times 6 \mathrm{~cm}$ felt on right lumbar to iliac fossa, which was mobile and there was rebound tenderness in the right iliac fossa, but no guarding. Per speculum examination showed pale vagina, mild bleeding through os. bimanual examination showed a tender mass of size around $8 \times 6 \mathrm{~cm}$ in posterior fornix. 
Fresh ultrasonography (USG) done which showed right complex ovarian mass, with empty uterus, further underwent blood test blood tests for alpha-fetoprotein (AFP) and lactate dehydrogenase (LDH), which were within normal limit (Figure 1).

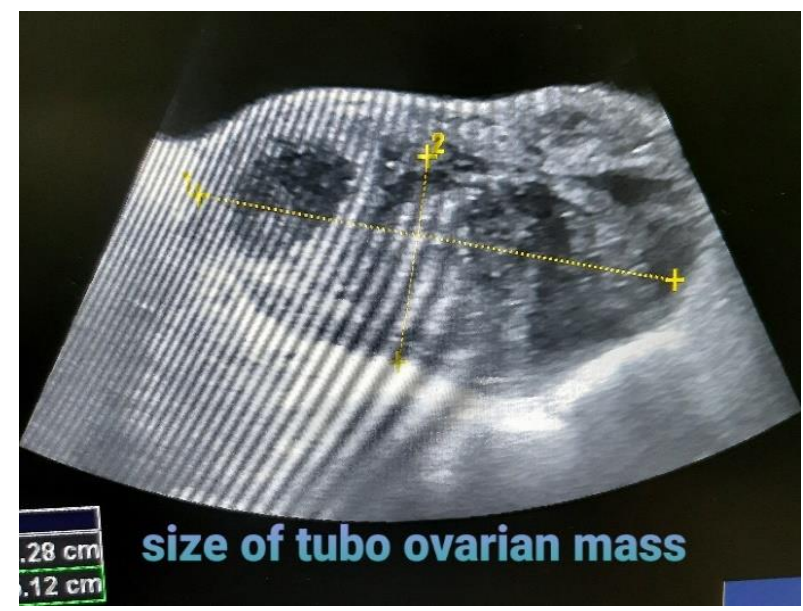

Figure 1: Size of tubo- ovarian mass on USG scan.

Her CA-125 was 119.30 IU/l, in view of above finding computed tomography (CT) pelvis and abdomen was done, which revealed a tubo-ovarian mass of size $10 \times 8 \mathrm{~cm}$ in right adnexa, suggestive of chronic ectopic pregnancy. Meanwhile UPT became negative on 5th day of hospital stay and got 5 unit of blood of a positive during her hospital stay prior to surgery. In view of above finding underwent an exploratory laparotomy group A positive, and there was evidence of chronic inflammation with mild small bowel adhesion and a cystic mass lesion in right fallopian tube, along with right ovary formed a complex mass which was densely adhered to the posterior surface of uterus. Because of extensive adhesions, the entire complex with the right tube and ovary were removed by right salpingo-oophorectomy (Figure 2).

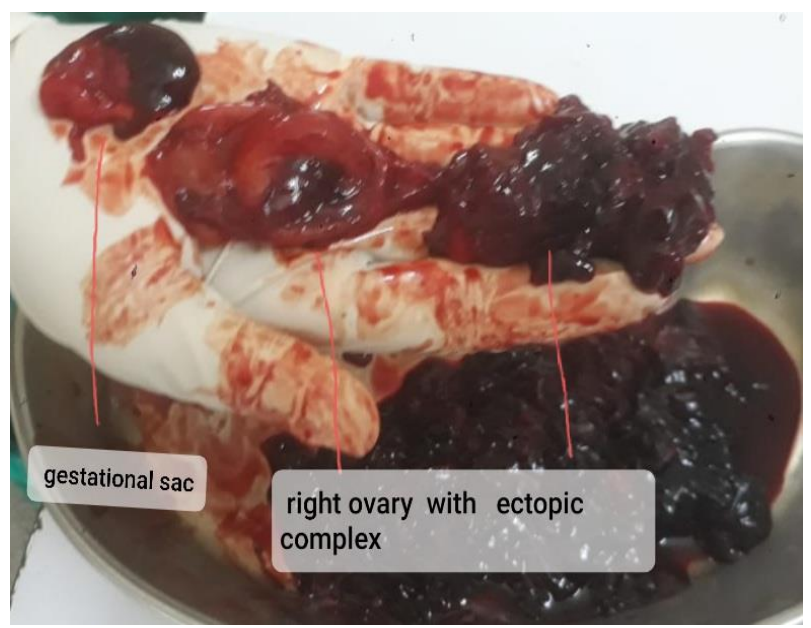

Figure 2: Ruptured gestational sac and complex mass consisted of extensive adhesion between right ovary and ectopic complex.
Right ovary could not be separated because of this we sacrificed right ovary. There was evidence of haemoperitoneum of around $500 \mathrm{ml}$. The left adnexa and the uterus were normal.

On macroscopic examination, the mass consisted of a normal ovary and measured $100 \times 80 \mathrm{~mm}$. Microscopic examination showed a dilated fallopian tube containing blood clot and trophoblast along with fibrin rich infarcted and viable chorionic villi, confirming the diagnosis of ectopic pregnancy. Got 2-unit blood post-operatively, recovered uneventfully and was discharged on the 8th post-operative day.

\section{DISCUSSION}

The incidence of ectopic pregnancy among all pregnancies is around $0.25-2 \%$ worldwide and it can occur in any sexually active woman of reproductive age. ${ }^{4}$ In India incidence of ectopic pregnancy is $0.91 \% .^{5}$ Often ectopic pregnancy may occur at a rate of 1:80 pregnancies or more. ${ }^{6}$ The diagnosis can be easily missed in the absence of classical symptoms of ectopic pregnancy. Approximately $43-55 \%$ of ectopic pregnancies do not present with the classical triad of lower abdominal pain, period of amenorrhea and vaginal bleeding., ${ }^{7,8}$

Because of wide spectrum of clinical presentation chronic ectopic pregnancy, it remains a conundrum for the gynaecologist. Of chronic ectopic pregnancy results from small recurrent bleed into pelvic peritoneal cavity which forms an organized clot in between the pelvic structures which is called pelvic hematocele. ${ }^{3}$ Sometimes the bleeding is confined to the tube itself with no peritoneal communication leading to the formation of a hematosalpinx..$^{9,10}$

The above-mentioned entities incite the formation of adhesions with the adjacent structures and these can clinically present as a pelvic or an abdominal lump as seen in our case. The inability to arrive at a definite diagnosis in our case was because the USG report which patient brought with herself from outside hospital was suggestive of left ovary teratoma along with history of dilation and evacuation and one more point which added confusion was presence of continuous severe pallor for that she got 5 unit blood pre-operatively. She was further investigated and the subsequent USG scan suggested a right complex ovarian mass. The sonographic appearance of chronic ectopic pregnancy is variable and nonspecific. It includes a nondiagnostic sonogam, a complex heterogeneous adnexal mass, and a highly vascular adnexal complex. ${ }^{11,12-15}$ The CA125 level was found to be 119.30 IU/l, which was above the normal range. The clinical and laboratory findings were pointing towards a large complex ovarian mass most probably of malignant potential, therefore CT scan done which showed large tubo-ovarian mass, therefore decision for exploratory laparotomy was taken. On laparotomy an unexpected large hematosalpinx was found and the histopathological examination of the 
specimen showed chorionic villi confirming chronic ectopic pregnancy (Figure 3). In short, investigations often mislead us and create biased opinion.

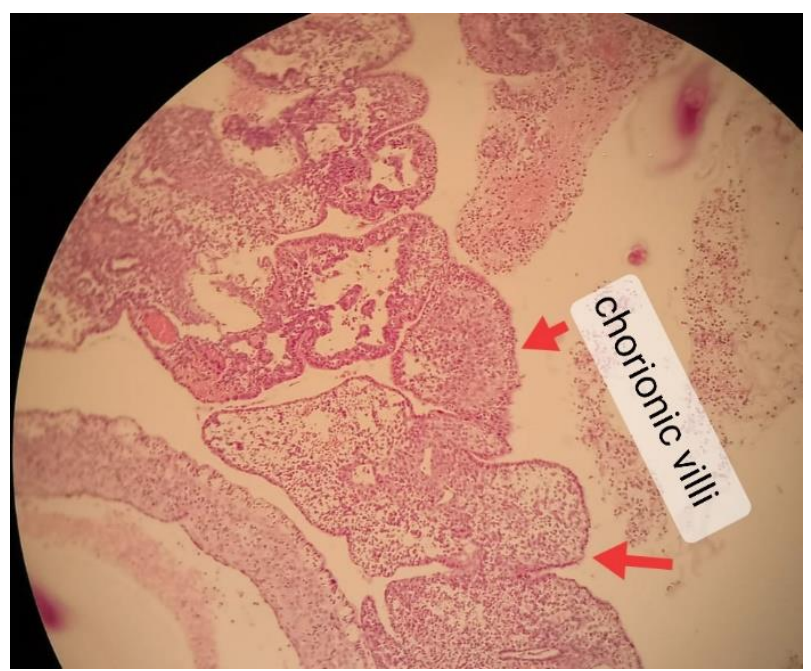

Figure 3: Histopathological finding.

\section{CONCLUSION}

In brief, it not only threatens the life if not treated timely and effectively, but also compromises the future fertility of the women. There were many factors which led to the diagnostic dilemma in our case. Same problem can be faced by other clinicians working in set-up like ours. Therefore, awareness about such rare cases can help us to broaden our clinical approach to save the precious life of the patient. And at last awareness about such rare cases is helpful in future clinical practice.

Funding: No funding sources Conflict of interest: None declared

Ethical approval: Not required

\section{REFERENCES}

1. Malhotra N, Malhotra J, Saxena R, Bora NM. Jeffcoate's Principles of gynaecology. 8th edition. New Delhi: Jaypee Brother Medical Publishers (P) Ltd. 2014;130.

2. Lau S, Tulandi T. Conservative medical and surgical management of interstitial ectopic pregnancy. Fertil Steril. 1999;72(2):207-15.

3. Ugur M, Turan C, Vicdan K, Ekici E, Oguz O, Gokmen O. Chronic ectopic pregnancy: a clinical analysis of 62 cases. Am J Obstet Gynecol. 1996;36(2):186.

4. Yadav A, Prakash A, Sharma S, Pegu B, Saha MK. Trends of ectopic pregnancies in Andaman and Nicobar Islands. Int J Repord Contracept Obstet Gynecol. 2017;6(1):15-9.

5. Tahmina S, Daniel M, Solomon P. Clinical Analysis of Ectopic Pregnancies in a Tertiary Care Centre in Southern India: A Six-Year Retrospective Study. J Clin Diagn Res. 2016;10(10):13-6.

6. Padubidri VG. Shaw's textbook of gynaecology. 17th edition. RELX India Pvt. Ltd. 2019;17:228.

7. Dialani V, Levine D. Ectopic pregnancy: a review. Ultrasound Q. 2004;20(3):105-17.

8. Wong E, Suat SO. Ectopic pregnancy: a diagnostic challenge in the emergency department. Eur J Emerg Med. 2000;7(3):189-94.

9. Nacharaju M, Vellanki VS, Gillellamudi SB, Kotha $\mathrm{V}$, Alluri A. A rare case of chronic ectopic pregnancy presenting as large hematosalpinx. Clin Med Insights Reprod Health. 2014;8:1-4.

10. Sindos M, Wang TF, Pisal N, Eben F, Singer A. Bilateral hematosalpinx in a case of ectopic pregnancy: a clinical dilemma. Am J Obstet Gynecol. 2003;189(3):892-3.

11. Barnhart KT, Rinaudo P, Hummel A, Pena J, Sammel MD, Chittams J. Acute and chronic presentation of ectopic pregnancy may be two clinical entities. Fertil Steril. 2003;80:1345-51.

12. Brennan DF, Kwartra S, Kelly M, Dunn M. Chronic ectopic pregnancy: two cases of acute rupture despite negative beta hCG. J Emerg Med. 2000;19:249-54.

13. Turan C, Ugur M, Dogan M, Ekici E, Vicdan K, Gokmen O. Transvaginal sonographic findings of chronic ectopic pregnancy. Eur J Obstet Gynecol Reprod Biol 1996;67:115-9.

14. Cole T, Corlett RC. Chronic ectopic pregnancy. Obstet Gynecol. 1982;59:63-8.

15. Abramov Y, Nadjari M, Shushan A, Prus D, Anteby SO. Doppler findings in chronic ectopic pregnancy: case report. Ultrasound Obstet Gynecol. 1997;9:3446.

Cite this article as: Sadangi $\mathrm{P}$, Ranjeeta $\mathrm{K}$, Jena $\mathrm{M}$. A rare case of chronic ectopic pregnancy: a diagnostic enigma. Int $\mathbf{J}$ Reprod Contracept Obstet Gynecol 2020;9:5118-20. 